\title{
Drug Release and Skin Penetration from Solid Lipid Nanoparticles and a Base Cream: A Systematic Approach from a Comparison of Three Glucocorticoids
}

\author{
P. Schlupp ${ }^{a, b} \quad$ T. Blaschke ${ }^{a} \quad$ K.D. Kramer ${ }^{a} \quad$ H.-D. Höltje W. Mehnert $^{\text {a }}$ \\ M. Schäfer-Korting ${ }^{a}$ \\ ${ }^{a}$ Institut für Pharmazie, Freie Universität Berlin, und ${ }^{b}$ Institut für Biochemie und Molekularbiologie, \\ Charité Universitätsmedizin Berlin, Berlin, und ' Institut für Pharmazeutische und Medizinische Chemie, \\ Heinrich-Heine-Universität, Düsseldorf, Deutschland
}

\section{Key Words}

Solid lipid nanoparticles · Glucocorticoids $\cdot$ Skin penetration $\cdot$ Drug release $\cdot$ Epidermal targeting

\begin{abstract}
Solid lipid nanoparticles (SLNs) can enhance drug penetration into the skin, yet the mechanism of the improved transport is not known in full. To unravel the influence of the drugparticle interaction on penetration enhancement, 3 glucocorticoids (GCs), prednisolone (PD), the diester prednicarbate (PC) and the monoester betamethasone 17-valerate (BMV), varying in structure and lipophilicity, were loaded onto SLNs. Theoretical permeability coefficients $(\mathrm{cm} / \mathrm{s})$ of the agents rank BMV (-6.38) $\geq$ PC (-6.57) > PD (-7.30). GC-particle interaction, drug release and skin penetration were investigated including a conventional oil-in-water cream for reference. Both with SLN and cream, PD release was clearly superior to $P C$ release which exceeded BMV release. With the cream, the rank order did not change when studying skin penetration, and skin penetration is thus predominantly influenced by drug release. Yet, the penetration profile for the GCs loaded onto SLNs completely changed, and differences between the steroids were almost lost. Thus, SLNs influence skin penetration by an intrinsic mechanism linked to a specific inter-
\end{abstract}

action of the drug-carrier complex and the skin surface, which becomes possible by the lipid nature and nanosize of the carrier and appears not to be derived by testing drug release. Interestingly, PC and PD uptake from SLN even resulted in epidermal targeting. Thus, SLNs are not only able to improve skin penetration of topically applied drugs, but may also be of particular interest when specifically aiming to influence epidermal dysfunction.

Copyright $\odot 2011$ S. Karger AG, Basel

\section{Introduction}

Human skin is tremendously efficient in protecting the organism against the uptake of xenobiotics including topically applied drugs. The stratum corneum, formed by corneocytes imbedded in a lipid matrix mainly composed of ceramides, cholesterol and free fatty acids $\left(\mathrm{C}_{24}{ }^{-}\right.$ $\mathrm{C}_{26}$ ), represents the primary barrier [1]. Surmounting this skin barrier is essential in the topical treatment of skin diseases. For about 20 years, solid lipid nanoparticles (SLNs) have been studied intensely as drug carrier system for parenteral $[2,3]$, peroral $[4,5]$ and dermal application $[6,7]$. The colloidal character (particle size between 100 and $500 \mathrm{~nm}$ ), the solid state of the particles and physio-

\section{KARGER}

Fax +41613061234 E-Mail karger@karger.ch www.karger.com

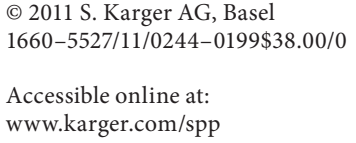

Monika Schäfer-Korting

Institut für Pharmazie, Freie Universität Berlin

Königin-Luise-Strasse $2+4$

DE-14195 Berlin (Germany)

Tel. +49308385 3283, E-Mail m.schaefer-korting@ fu-berlin.de 
Table 1. Physicochemical data of PD, PC and BMV and QSPR

\begin{tabular}{lccc}
\hline & PD & PC & BMV \\
\hline $\mathrm{MW}, \mathrm{g} / \mathrm{mol}$ & 360.45 & 488.57 & 476.58 \\
$\mathrm{MV}, \mathrm{cm}^{3} / \mathrm{mol}$ & 274.7 & 388.5 & 382.3 \\
$\mathrm{PSA}, \AA^{2}$ & 94.8 & 116.2 & 100.9 \\
$\log \mathrm{P}$ & 1.69 & 3.82 & 3.98 \\
$\log \mathrm{K}_{\mathrm{p}}$ & -7.30 & -6.57 & -6.38 \\
\hline
\end{tabular}

$\mathrm{MW}=$ Molecular weight MV = molecular volume; $\mathrm{PSA}=$ polar surface area; $\log \mathrm{P}=$ octanol-water partition coefficient; $\mathrm{K}_{\mathrm{p}}=$ permeability coefficient; QSPR = quantitative structure-permeability relationship.

logical lipids forming the particle matrix, as well as welltolerated surfactants used for particle stabilization, make SLNs an interesting alternative to other nanosized systems, such as liposomes, nanostructured lipid carriers, microemulsions and polymeric particles for improving skin therapy $[8,9]$. Yet, until today there is only limited data on the mechanism of drug transport into the skin $[7$, 10]. Making contact with the skin surface, the carrier matrix appears to dissolve, and this favors the interaction of carrier lipids and skin lipids and the penetration of the loaded guest molecules [11-13]. Interestingly, uptake from SLNs is clearly superior to uptake from particles built up from both solid lipids and oils (nanostructured lipid carriers) [14, 15]. Active pharmaceutical ingredients or marker agents (dyes or spin probes) can be incorporated into the lipid matrix of SLNs [14] or attached to the particle surface [15-18]. In fact, even subcompartments of spin probe localization have been observed [16]. Uptake enhancement is 4 - to 8 -fold over cream with dyes incorporated or attached, whereas epidermal targeting was seen only with guest molecules attached to the surface $[15,18,19]$.

To unravel the mechanism of SLN enhanced uptake in more detail, we studied the skin penetration of glucocorticoids (GCs): prednisolone 17-ethylcarbonate 21-propionate (prednicarbate, PC) and betamethasone 17-valerate $(\mathrm{BMV})$ - which are frequently used in the treatment of inflammatory skin diseases $[9,20]$ - as well as prednisolone (PD). The $3 \mathrm{GCs}$ are close in molecular weight and molecular volume but vary in lipophilicity (octanol-water partition coefficient) and structure (table 1). Aiming for a deeper insight into carrier-related effects on drug concentrations at the active site, drug release and skin penetration were compared from SLN dispersion and an oil-in-water cream (DAC Cremor basalis). Investigations of drug release and skin penetration in parallel are crucial to estimate the potential of a drug carrier system and most importantly - to unravel the carrier effect on skin penetration.

\section{Material and Methods}

\section{Material}

The GCs betamethasone (BM), PD and BMV were supplied by Sigma-Aldrich (Munich, Germany); PC was a gift from SanofiAventis (Frankfurt a.M., Germany). Compritol ${ }^{\circledR} 888$ ATO (glyceryl behenate) was a gift from Gattefossé (Weil a.Rh., Germany), the surfactant Poloxamer ${ }^{\circledR} 188$ was supplied by BASF (Ludwigshafen, Germany) and base cream (Cremor basalis, oil-in-water cream, as described by the Deutscher Arzneimittelcodex 2004, containing glycerin monostearate $4 \%$, cetylalcohol $6 \%$, macrogol 20 -glycerol monostearate 7\%, medium-chain triglycerides $7.5 \%$, propylene glycol $10 \%$, white vaseline $25.5 \%$ and water $40 \%$ ) was obtained from Caelo (Hilden, Germany). All other reagents were supplied by VWR (Darmstadt, Germany) and were of the highest quality available.

\section{Methods}

Preparation of GC-Loaded SLN Dispersion and Cream

SLNs, composed of $10 \%$ Compritol ${ }^{\circledR} 888$ ATO, $2.5 \%$ Poloxamer ${ }^{\circledR} 188$ and $0.1 \%(0.075-0.3 \%$ for the parelectrical spectroscopy) of a GC, were prepared by high-pressure homogenization as described previously $[14,21]$. Briefly, the lipid was melted at approximately $95^{\circ} \mathrm{C}$ to dissolve or disperse the GC. Following the addition of the aqueous surfactant solution of about $85^{\circ} \mathrm{C}$, a premix was formed using a rotor-stator mixer and was then passed through the homogenizer (EmulsiFlex C5; Avestin, Mannheim, Germany) at $90^{\circ} \mathrm{C}$ and 500 bar. The homogenizer ran continuously for $2.5 \mathrm{~min}$ equivalent to 3 cycles for $20 \mathrm{~g}$ of the dispersion. The obtained nanoemulsion was gently cooled down to room temperature without stirring to form SLNs. All dispersions were stored in silanized vials at $8^{\circ} \mathrm{C}$ for up to 3 months.

To produce a GC-loaded cream, small amounts of the base cream were added to the GC and homogenized at ambient temperature using a pestle and mortar until the final GC concentration of $0.1 \%$ was obtained.

\section{Characterization of the SLNs}

Mean particle size (z-average) and the polydispersity index (PI, a measure of the distribution width) were determined by photon correlation spectroscopy (Malvern Zetasizer Nano-ZS, Malvern Instruments, Malvern, UK). In addition, laser diffractometry (LD, Coulter LS 230; Miami, Fla., USA) served to detect larger particles; the maximum size of $95 \%$ of the volume of the particles (LD95) is reported. The diffraction patterns were analyzed using the Mie model (fluid refractive index of 1.335, real sample refractive index of 1.456 and imaginary sample refractive index of 0.01 ). Recrystallization of the GCs during the storage of the particles was inspected by polarized light microscopy (Leitz-Orthoplan; Leica, Wetzlar, Germany). The methods are described in detail elsewhere $[10,22]$. Furthermore, the lipid dispersions were analyzed by differential scanning calorimetry (DSC, Mettler DSC 
$821^{\mathrm{e}}$; Mettler Toledo, Giessen, Germany). Samples of about $20 \mathrm{mg}$ were accurately weighted in $40-\mu$ l aluminum pans. DSC scans were recorded from 15 to $85^{\circ} \mathrm{C}$ with a heating rate of $5^{\circ} \mathrm{C} / \mathrm{min}$. The recrystallization of the lipid nanoparticles was examined, and the crystallization index CI was calculated from the enthalpy of the SLN and the bulk material of the lipid Compritol [23]:

$C I(J / g)=\frac{\text { enthalp }_{S L N}(\mathrm{~J} / \mathrm{g})}{\text { enthalp }_{\text {bulk }}(\mathrm{J} / \mathrm{g})} \cdot$ concentration $_{\text {lipid phase }}(\%) \cdot 100$

Interaction of the GCs and SLNs was studied by parelectric spectroscopy. The theoretical background and the method are described in detail elsewhere $[16,24]$. Briefly, the dependence of particle mobility and density of the dipoles on the increasing drug concentration $(0-0.3 \%$ of the GC) was measured by a frequency analyzer (type ZVR, Rohde and Schwarz, München, Germany). Results allow to distinguish between attachment of a guest molecule to the surface (parabolic relationship) or the incorporation of the agent into the matrix of a carrier system (linear relationship).

\section{Drug Release Studies}

GC release from SLNs and cream was studied using Franz diffusion cells $[25,26], 15 \mathrm{~mm}$ in diameter (surface area $1.76 \mathrm{~cm}^{2}$ ) and of $12 \mathrm{~cm}^{3}$ volume of the receiver chamber (PermeGear, Bethlehem, Pa., USA). A presoaked polyamide membrane (pore size $0.2 \mu \mathrm{m}$, diameter $25 \mathrm{~mm}$, Sartorius AG, Goettingen, Germany) separated the donor and the receptor compartments. The receptor fluid (phosphate-buffered saline, PBS, pH 7.4) was continuously stirred at $500 \mathrm{rpm}$; the temperature was maintained at $33.5^{\circ} \mathrm{C}$ by a circulating water bath. An infinite dose $(500 \mu \mathrm{l})$ of the formulation was applied after $30 \mathrm{~min}$ equilibration, removal of a $500-\mu \mathrm{l}$ predose sample of the receptor fluid and replacement by fresh PBS. The donor compartment was sealed with Parafilm ${ }^{\circledR}$ to prevent evaporation of the formulation. Further aliquots of $500 \mu \mathrm{l}$ receptor fluid were withdrawn repeatedly $(0.33,0.66,1,2,3,4,5,6,7$ and $8 \mathrm{~h}$; with replacement) and stored at $-20^{\circ} \mathrm{C}$. The samples were analyzed by high-performance liquid chromatography (HPLC) after extraction. The cumulative GC amount released, expressed in micrograms per square centimeter, is plotted against the square root of time $\left(h^{0.5}\right)$ [27], also called Higuchi plot. The flux, the mass of test substance passing through a unit area of the membrane $(1.76$ $\mathrm{cm}^{2}$ ) per unit of time under steady-state conditions (in $\mu \mathrm{g} / \mathrm{cm}^{2} /$ $\mathrm{h}^{0.5}$ ) as well as the relative lag time (abscissa intercept point, $\mathrm{h}^{0.5}$ ) were calculated from the slope of the graph [28] using an automated approach [29] adjusting the $\mathrm{h}^{0.5}$ time. All experiments were repeated 9 times, and the average values were taken.

\section{Skin Penetration Studies}

Using human skin, cutaneous absorption can be studied ex vivo by a validated test protocol $[30,31]$. Human full-thickness abdominal or breast skin was from females aged 18-69 years (with permission) subjected to plastic surgery. Placed in ice-cold cloth, skin was transferred to the laboratory immediately, taking care to avoid contamination of the skin surface by subcutaneous lipids and stored frozen at $-20^{\circ} \mathrm{C}$ for at least $24 \mathrm{~h}$, not exceeding 6 months. On the day of experiment, thawed skin was mounted into the Franz diffusion cells, the stratum corneum facing the air and the lower surface in contact with the magnetically stirred receptor fluid. The experimental setup was identical with that of the re- lease study. After equilibration for $30 \mathrm{~min}, 500 \mu \mathrm{l}$ (infinite dose) of the formulation was applied to the skin surface for $6 \mathrm{~h}$. Then surplus material was carefully removed by a cotton swab soaked in PBS, and the skin was stripped twice with adhesive tape; the tape strips with remaining nonabsorbed GC were discarded. Skin samples were stored at $-20^{\circ} \mathrm{C}$. In order to quantify the $\mathrm{GC}$ amount in the different skin layers, the skin samples were cut at $-24^{\circ} \mathrm{C}$ into horizontal slices of $50 \mu \mathrm{m}$ using a freeze-microtome (Frigocut 2800 N; Leica Microsystems, Bensheim, Germany). Two consecutive slices were pooled and $500 \mu \mathrm{l}$ of a saturated sodium fluoride solution $(120 \mathrm{mg} / \mathrm{ml})$ were added to inhibit esterases of the skin [32]. The samples were analyzed by HPLC to quantify native GCs and metabolites in the different skin layers $(0-400 \mu \mathrm{m}$; steps of $100 \mu \mathrm{m})$ after 6-hour exposure. Results are expressed as the amount of total drug, each representing the native drug (PD, PC and BMV) plus its degradation products or metabolites, respectively.

Uptake by human skin was studied in triplicate (skin of 3 donors) and at least 3 repetitions for cream and SLN $(n=3)$, respectively. GC-loaded SLN dispersions were tested in parallel using the skin of the same donors. This holds also true when testing GC creams.

Quantification of the GCs

PC, BMV and their degradation products as well as PD were quantified by HPLC (LaChrom ${ }^{\text {TM }}$ HPLC system; Merck-Hitachi, Darmstadt, Germany) [19, 32]. BM served as internal standard for PD and PC determination, whereas PD was the internal standard of BMV quantification. Since GC 21-esters can be cleaved by skin esterases [32] and GC 17-monoesters are degraded nonenzymatically [33] and may also rearrange spontaneously to the respective more stable 21-esters [34-36], formulations, receptor fluid and skin were analyzed for degradation products. Prednisolone 17-ethylcarbonate (P17EC), prednisolone 21-ethylcarbonate (P21EC) and betamethasone 21-valerate (BM21V) were identified according to their retention times determined previously and quantified by relating UV absorbance (peak area) to PC or BMV, respectively. The retention times are PD 6.9 min, BM 8.3 min, P17EC 9.8 min, P21EC 11.1 min, BMV 13.0 $\mathrm{min}, \mathrm{PC} 13.6 \mathrm{~min}$ and BM21V $14.0 \mathrm{~min}$. Limits of quantification are $61 \mathrm{ng} / \mathrm{ml}$ (PC), $90 \mathrm{ng} / \mathrm{ml}(\mathrm{PD}), 98 \mathrm{ng} / \mathrm{ml}(\mathrm{BM})$ and $119 \mathrm{ng} / \mathrm{ml}$ $(\mathrm{BMV})$. The linear correlation of peak area and concentration is given up to $50 \mu \mathrm{g} / \mathrm{ml}$ (correlation coefficient $>0.994$ ).

To verify the GC concentration in creams and SLN dispersions and to check for potential hydrolysis of GC esters (PC, BMV), all preparations were extracted and subjected to HPLC analysis. 100 $\mathrm{mg}$ of cream was dispersed in $10 \mathrm{ml}$ of chloroform following addition of internal standard ( $100 \mu \mathrm{l}$ of $10^{-4} \mathrm{M}$ GC in methanol). The samples were vortexed, and $1 \mathrm{ml}$ of the solution was withdrawn and exsiccated by vacuum rotation. Residues were extracted 3 times by $500 \mu \mathrm{l}$ of methanol. The combined extracts were once more exsiccated in a vacuum. The SLN dispersions were diluted $1: 100$, and the internal standard was added $\left(20 \mu \mathrm{l}\right.$ of $10^{-4} \mathrm{M} \mathrm{GC}$ in methanol). Samples were extracted 3 times by $500 \mu$ l of ethyl acetate, and the combined extracts were exsiccated by vacuum rotation. Residues were dissolved in $500 \mu \mathrm{l}$ methanol and the exsiccation was repeated. Finally the extracts from the creams and SLN dispersions were dissolved in $200 \mu \mathrm{l}$ methanol, centrifuged and subjected to the HPLC. 
For the analysis of drug release and skin penetration, GCs and their metabolites were quantified in PBS (receptor fluid) and excised human skin (skin penetration only). While receptor fluid was extracted immediately after defrosting, the skin slices in saturated sodium fluoride solution were first subjected to 5 freezethaw cycles to disrupt membranes before extraction. Following the addition of the internal standard, the samples were extracted 3 times by $500 \mu \mathrm{l}$ of ethyl acetate. The combined extracts were exsiccated by vacuum rotation, dissolved in $500 \mu \mathrm{l}$ of methanol and exsiccated again. The residues were dissolved in $100 \mu \mathrm{l}$ of methanol and $50 \mu \mathrm{l}$ were injected into the HPLC. Recovery of the steroids was $75 \%$ from human skin [32] and exceeded 82\% from PBS [34].

Calculation of Physiochemical Data, Quantitative

Structure-Permeability Relationship (QSPR)

Besides molecular weight and lipophilicity, molecular polar surface area is reported to influence drug transport $[37,38]$. To include this parameter, polar surface area calculation was performed as described [38]. Furthermore, the molecular volumes of the 3 steroids were calculated using the ACD/Labs Software (Advanced Chemistry Development Inc., Ontario, Calif., USA) and the permeability coefficient $K_{p}$ as described by Potts and Guy [39]:

$$
\log \mathrm{K}_{\mathrm{p}}(\mathrm{cm} / \mathrm{s})=0.71 \log \mathrm{P}-0.0061 \cdot \mathrm{MW}-6.3
$$

where $\log \mathrm{P}=$ octanol-water partition coefficient and $\mathrm{MW}=\mathrm{mo}$ lecular weight.

\section{Data Analysis}

Data are given as arithmetic mean values \pm standard deviation. Additionally, the results of GC skin penetration are summarized in a box plot with the median, the minimum, the maximum and the 0.25 and 0.75 quartiles. In order to verify the differences of the drug release $(n=9)$, data were subjected to the nonparametric Kruskal-Wallis test, followed by the Dunn/Bonferroni procedure, in case of significance (GraphPad Prism ${ }^{\circledR}$ version 5.03). Thus $\mathrm{p} \leq 0.05$ is regarded to indicate a difference.

\section{Results and Discussion}

Physicochemical properties of the active agents (table 1) as well as the characteristics of the formulation (excipients and dosage form) influence skin penetration. Investigations on drug release and skin penetration are indispensable to optimize the formulations for a topical therapy as insufficient drug release can result in low uptake by the skin. Moreover, these experiments are also needed for a deeper insight into the interaction of skin, carrier system and the active ingredient, and for understanding the function of the carrier systems when aiming at advanced technological approaches.

\section{Characterization of the Formulations}

Particle size, drug loading, drug stability and the physical state of the lipid are the major properties under investigation for a characterization of the physical and chemi- cal (long-term) stability of the SLNs [10, 40]. SLN dispersions, both loaded with the 3 GCs and nonloaded, were characterized on day 1 and day 39 after production by determination of particle size by LD and photon correlation spectroscopy, phase transition of the lipid matrix with DSC and GC expulsion by polarized light microscopy. Moreover, HPLC was used to quantify the concentrations of the active agents and to inspect for degradation products caused by the thermal load during production.

The main purpose of this study, however, was to examine the GC-particle interaction and its influence on skin penetration. Therefore, SLNs uniform in size and crystallinity were produced according to a standardized protocol. While PC and BMV were soluble in the lipid, PD was dispersed in the lipid matrix after heating for $1 \mathrm{~h}$ to about $95^{\circ} \mathrm{C}$. Destroying any crystal lattice of the bulk material by a sufficiently long heating period above the melting point is recommended in order to avoid the lipid memory effect and to enable a new crystallization. Furthermore, the solubility is a time-depending step but has to be in accordance with the thermostability of the agent. The mean particle size of the 3 SLN dispersions was $173 \pm 4 \mathrm{~nm}$ with a PI of $0.14 \pm 0.02$ on day 1 ; size and size distribution did not change within 39 days (photon correlation spectroscopy: $175 \pm 5 \mathrm{~nm}$ and PI $0.17 \pm 0.01$ ). LD measurements confirm this result (LD95: $272 \pm 9 \mathrm{~nm}$ day 1 and $280 \pm$ $10 \mathrm{~nm}$ day 39), microparticles were not detectable by LD and light microscopy. The GC-free SLNs were close in particle size (mean $169 \mathrm{~nm}$, PI 0.13, LD95 $267 \mathrm{~nm}$ ).

The mode of GC-lipid interaction during the production process turned out to be relevant for stability. Whereas PC and BMV could be dissolved in the melted lipid, PD was dispersed. By light microscopy PD crystals were detected in the $0.1 \%$ PD SLN dispersion after 1 week, whereas the $0.1 \%$ PC and the $0.1 \%$ BMV SLN dispersions were stable for at least 4 weeks. Hence, drug release and skin penetration studies were carried out within 3 days after production. Additional investigations showed a time dependence of the drug expulsion in relation to the lipidGC ratio. Drug crystals were detected after $24 \mathrm{~h}$ with a $0.3 \%$ PC-loaded SLN dispersion (same composition), yet a $0.075 \%$ PC-loaded SLN dispersion was stable for more than 3 months. Crystallization is due to a progressive cure of lattice imperfections during storage. Most of the triglyceride matrix is present in the highly organized $\beta$ modification limiting the drug loading capacity of SLNs composed of triglycerides [23]. DSC results revealed high crystallinity of the SLNs made of Compritol (crystallization index $94 \pm 3 \%$ ) not increasing upon storage, which is well in accordance with other triglycerides [23, 41]. 
On the first day after production the GC concentrations in the SLN dispersions were quantified by HPLC. BMV SLNs (loading 106.8 $\pm 1.4 \%$ of target value) showed limited thermal stability after homogenization as BMV made up $87.2 \pm 0.2 \%$ of the total GC, and the degradation products BM21V (12.5 $\pm 0.2 \%)$ and $\mathrm{BM}(0.3 \pm$ $0.0 \%)$ could be detected in relevant amounts. In contrast, with PC (103.1 $\pm 3.2 \%$ of target value) degradation products were below the limit of quantification. Surprisingly, just $82.5 \pm 3.5 \%$ of PD was found in the final SLN dispersion; an additional peak appearing in the HPLC chromatogram at 8.3 min suggests that $\mathrm{PD}$ undergoes degradation during the production. Quantifying this peak by relating UV absorbance (peak area) to PD led to the assumption that the additional peak $(18.4 \pm 7.7 \%)$ represents a degradation product, matching the missing drug amount. In fact, the sum of PD and the degradation product was $100.9 \pm 6.2 \%$ of the target value. PD is susceptible to degradation which involves the 20-keto group resulting in the formation of the respective 17-ketosteroid [42]; instability is enhanced by higher temperatures [43]. Verification of this product, however, was excluded as a reference substance was not available. The degradation product was considered in the calculation of drug release and skin penetration, whenever it appeared.

GC concentrations in the creams were quantified, too. PC (total $103.9 \pm 2.7 \%$; $98.3 \pm 1.3 \%$ PC and $1.7 \pm 1.3 \%$ P17EC) and BMV (total 100.7 \pm 5.8\%; $93.5 \pm 1.9 \%$ BMV, $5.9 \pm 1.7 \% \mathrm{BM} 21 \mathrm{~V}$ and $0.6 \pm 0.2 \% \mathrm{BM}$ ) showed only minor degradation. This is well explained by the lack of a heating step. Once more, the concentration of PD (95.8 \pm $2.7 \%$ ) in the cream was slightly below the target concentration, but no additional peak was detected. Since GC release and skin penetration experiments used the infinite dose approach, the small discrepancy is negligible.

Results of the parelectric spectroscopy revealed a linear relation of dipole mobility and the GC concentration (data are not shown). Thus, the 3 steroids were incorporated in the lipid matrix of the SLNs. Earlier studies [19] indicated that SLN composition and production parameters strongly influence the drug-particle interaction.

\section{GC Release: Cream}

Drug release studies were performed using a Franz diffusion cell with a polyamide membrane as diffusion barrier. The cumulative amount of GC released $\left(\mu \mathrm{g} / \mathrm{cm}^{2}\right)$ is plotted against the square root of time $\left(h^{0.5}\right)$. For topical formulations a linear relationship between the drug released and the square root of time was shown, if less than $30 \%$ of the applied drug is released [44]. This holds true both with active agents fully dissolved [45] or suspended in the formulation [46].

Figure 1a shows steroids released from the cream versus the square root of time; all 3 steroids were slowly released. Yet, PD was released clearly faster than PC and BMV. After $8 \mathrm{~h}$ almost $9 \%$ of PD was released $(44.3 \pm 4.5$ $\mu \mathrm{g})$ but less than $1 \%$ of the other steroids ( $4.3 \pm 0.4$ and $1.8 \pm 0.2 \mu \mathrm{g}$ for PC and BMV, respectively; $\mathrm{p} \leq 0.05$ ). Table 2 summarizes the calculated kinetic constants, fluxes and relative lag times of the systems. The flux of PD exceeding PC and BMV flux 8.5- and 15-fold ( $\mathrm{p} \leq$ 0.05 ), underlines a clear superiority of the PD cream when aiming for fast release. Moreover, the short relative lag times, ranging from $0.2 \pm 0.0 \mathrm{~h}^{0.5}$ (PD) to $1.2 \pm$ $0.2 \mathrm{~h}^{0.5}$ (BMV), prove that the polyamide membrane is highly permeable for the steroids and that membrane retention is not the rate-limiting step. The inner structure of the cream and the physicochemical properties of the GCs (table 1) can explain the release pattern. Dissolution of the steroids by the cream (oil-in-water emulsion) was given as no GC crystals were detectable by light microscopy. Due to the 2-phase system of the cream, the agents will be partitioned between the inner oil and the outer aqueous phase. Surely, the less lipophilic PD is dissolved to a higher level in the outer water phase and can pass the membrane much faster than highly lipophilic PC and BMV which will be favorably dissolved in the inner lipid phase of the cream and therefore have a longer diffusion pathway. Thus, GC release from the cream is a function of the physicochemical properties of the active agent, meaning its partition between the water and the oil phase of the cream.

Investigating $\mathrm{GC}$ release from cream, no PC and PD degradation products were found in the receptor fluid. However, BMV proved less stable. BMV (77.6 $\pm 3.2 \%)$ was the main steroid in the receptor fluid after $8 \mathrm{~h}$, followed by the more stable isomer [34] BM21V (22.0 \pm $3.2 \%)$ and the hydrolysis product $\mathrm{BM}(0.4 \pm 1.2 \%)$. This result is in accordance with the limited stability of BMV $\left(43.4 \pm 3.8 \% \mathrm{BM} 21 \mathrm{~V}, 8 \mathrm{~h}, 33.5^{\circ} \mathrm{C}\right)$ in $\mathrm{PBS}$ and a previous report on BMV diffusion of a living skin equivalent [33] and higher stability of PC $(3.3 \pm 0.3 \%$ PC17EC; $3.8 \pm$ $0.3 \% \mathrm{P} 21 \mathrm{EC}, 8 \mathrm{~h}, 33.5^{\circ} \mathrm{C}$ ).

\section{GC Release: SLNs}

Release profiles of SLNs can be controlled by the lipid matrix, surfactant concentration and production conditions (e.g. temperature) [21, 47]. As with the cream, GC release ranged in the order PD $>>P C>$ BMV (fig. 1b; $p \leq 0.05)$. PD release from SLNs appears to follow a 
Fig. 1. Cumulative GC amounts released from cream (a) and SLNs (b); means $\pm \mathrm{SD}$; - = PD; $>$ PC; 0 = BMV; $500 \mu \mathrm{g}(284.1$ $\mu \mathrm{g} / \mathrm{cm}^{2}$ ) were applied to a polyamide membrane (Higuchi plot).

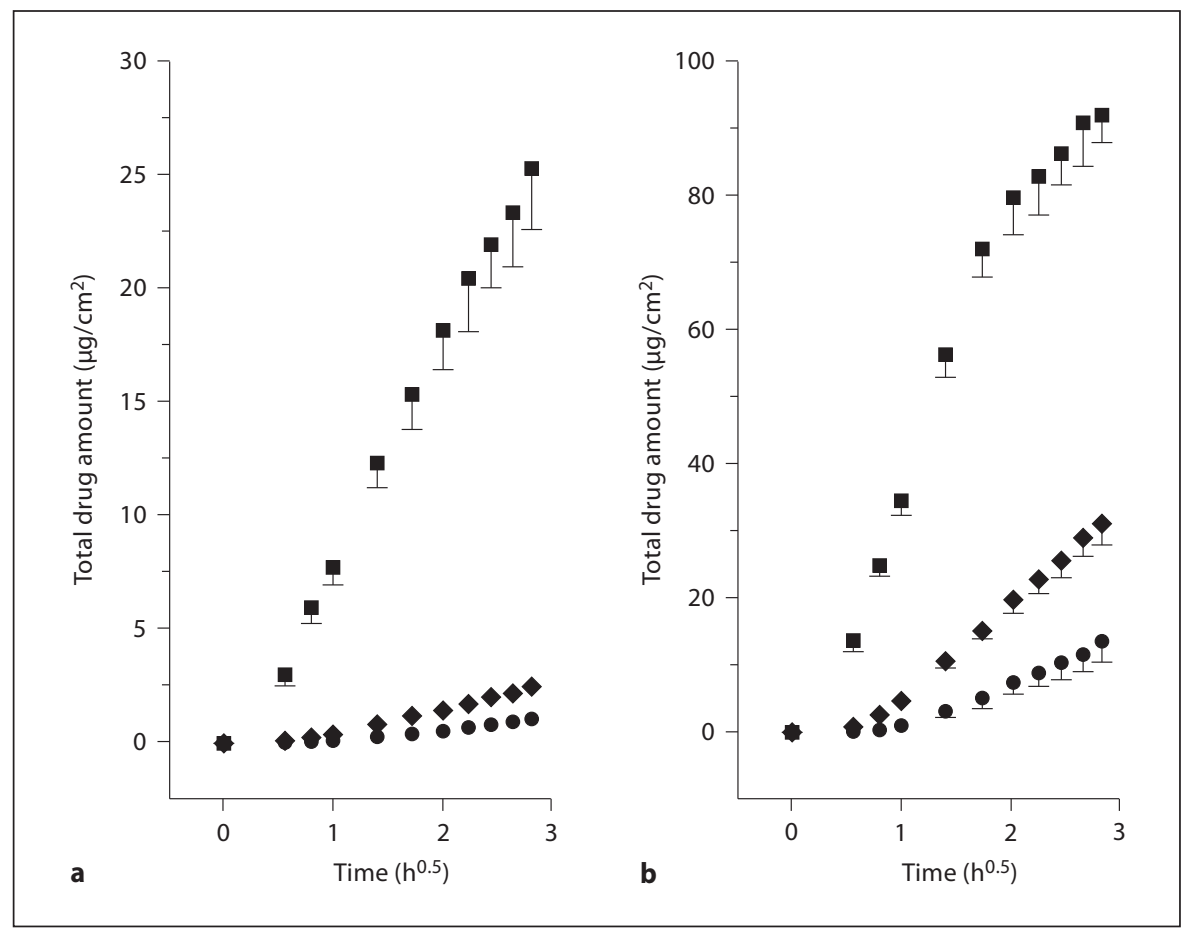

Table 2. Results of the GC release studies

\begin{tabular}{llll}
\hline & PD & PC & BMV \\
\hline Cream & & & \\
Flux, $\mu \mathrm{g} / \mathrm{cm}^{2} / \mathrm{h}^{0.5}$ & $9.90 \pm 0.80$ & $1.16 \pm 0.14^{*}$ & $0.65 \pm 0.07^{*}$ \\
Relative lag time, $\mathrm{h}^{0.5}$ & $0.21 \pm 0.03$ & $0.73 \pm 0.15^{*}$ & $1.24 \pm 0.22^{*}$ \\
$\mathrm{R}^{2}$ & 0.995 & 0.987 & 0.985 \\
\hline SLNs & & & \\
Flux, $\mu \mathrm{g} / \mathrm{cm}^{2} / \mathrm{h}^{0.5}$ & $43.44 \pm 7.42$ & $14.62 \pm 1.69^{*}$ & $7.30 \pm 1.59^{*}$ \\
Relative lag time, $\mathrm{h}^{0.5}$ & $0.17 \pm 0.13$ & $0.68 \pm 0.10^{*}$ & $1.03 \pm 0.11^{*}$ \\
$\mathrm{R}^{2}$ & 0.982 & 0.994 & 0.986 \\
\hline
\end{tabular}

$500 \mu \mathrm{g}$ GC SLN dispersions or creams were applied for $8 \mathrm{~h}$. Relative lag time and flux are given as mean values \pm SD $(n=9)$; data were subjected to Higuchi plot analysis; ${ }^{*} \mathrm{p} \leq 0.05$ versus PD.

2-phase kinetics (fig. 2): at $3 \mathrm{~h}$ about 25\% of PD was released but just another $7 \%$ in the following $5 \mathrm{~h}$. As PD solubility is $142 \mu \mathrm{g} / \mathrm{ml}$ in water [48] and $223 \mu \mathrm{g} / \mathrm{ml}$ in different buffers [49], a sink condition during the experiment $(13.5 \mu \mathrm{g} / \mathrm{ml})$ was provided. Studying Compritolbased SLNs, zur Mühlen and Mehnert [21] observed a similar biphasic release profile for $\mathrm{PD}$, too, changing with the production conditions and the lipid matrix. The rather high aqueous solubility of PD and the high temperature during the production should allow PD to partition between the two phases $[47,50]$. In contrast, the highly lipophilic PC and BMV appear to remain within the lipid matrix since prolonged release and obviously 1-phase kinetics are observed (fig. 2).

GCs were released much faster from SLNs compared to the cream (fig. 1). Kinetic constants obtained from PC and BMV loaded to SLNs exceeded those following the respective cream more than 10 -fold. PD release from SLNs was higher than from the cream, too, but less enhanced than PC and BMV release (table 2). After $8 \mathrm{~h}$, $162.2 \pm 7.2 \mu \mathrm{g}$ of PD (i.e. about $30 \%$ of the total GC loaded), $54.6 \pm 5.3 \mu \mathrm{g}$ of PC (10.9\%) and $23.5 \pm 5.0 \mu \mathrm{g}$ of BMV (4.7\%) were released from the SLNs. Relative lag times corresponded to those for creams ranging from 0.2 $\pm 0.1 \mathrm{~h}^{0.5}(\mathrm{PD})$ to $1.0 \pm 0.1 \mathrm{~h}^{0.5}(\mathrm{BMV})$. The higher kinetic constants for SLN dispersions can be attributed to the lower viscosity of the outer aqueous phase [28] and to the increased thermodynamic activity of the GCs in the SLN dispersion due to the higher water content and therefore a decrease in the GC solubility in the formulation. Investigating volunteers Wirén et al. [51] showed a higher activity of BMV (skin blanching) and benzyl nicotinate (erythema induction) by lowering the fat content in topi- 


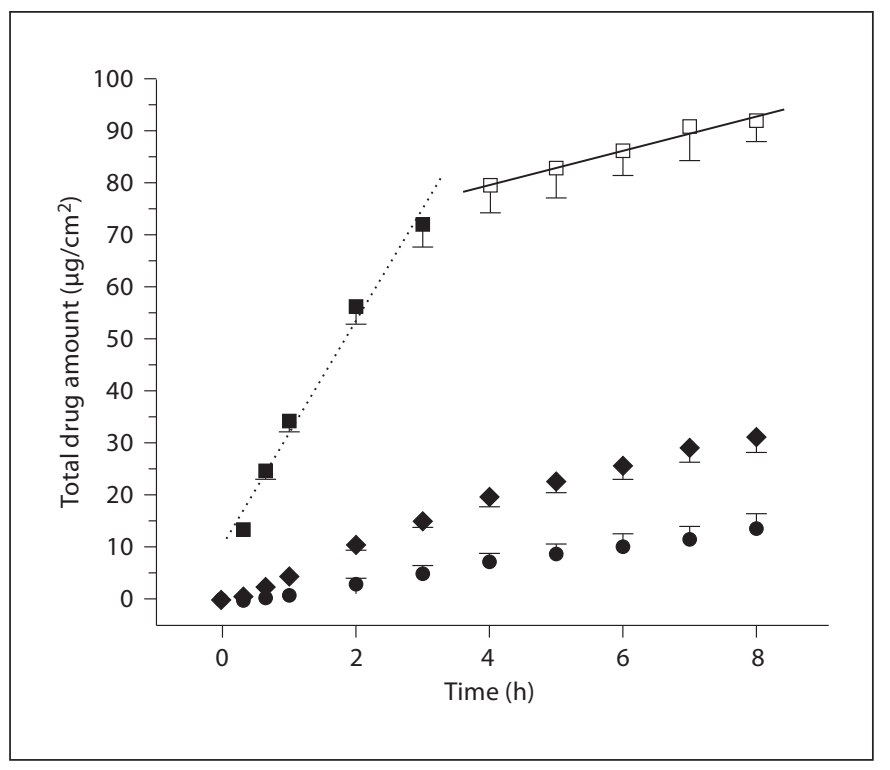

Fig. 2. Cumulative GC released from SLNs (means $\pm \mathrm{SD}$ ); $\mathbf{\square}=$ PD 0.33-3 h, slope $=9.99 \mu \mathrm{g} /\left(\mathrm{cm}^{2} / \mathrm{h}\right), \mathrm{R}^{2}=0.983 ; \square=$ PD $4-8 \mathrm{~h}$, slope $3.29 \mu \mathrm{g} /\left(\mathrm{cm}^{2} / \mathrm{h}\right), \mathrm{R}^{2}=0.980 ;-\mathrm{PC} ; \bullet=\mathrm{BMV}$.

cal formulations which is attributed to a higher increase in drug concentration in the lower fat formulations with water evaporation when applied to the skin. A change of the thermodynamic activity caused by water evaporation during our experiments was, however, minimized, sealing the donor compartment with Parafilm, and this cannot explain the superiority of drug delivery by SLNs as compared to the cream.

When testing GC-loaded SLNs, once more native PC $(98.2 \pm 0.8 \%$ after $8 \mathrm{~h})$ and PD $(99.6 \pm 0.1 \%)$ were the main analytes detected in the receptor fluid, whereas BMV made up only $70.8 \pm 3.2 \%$ and the degradation products BM21V $(26.8 \pm 2.7 \%)$ and BM $(2.4 \pm 0.6 \%)$ were detectable in relevant amounts. Taken together, GC release from SLN is clearly superior to GC release from cream.

\section{Skin Uptake Studies: Cream}

Drug release is of fundamental importance for topically applied formulations, yet the stratum corneum is the main barrier drugs have to overcome to penetrate into viable skin. Whereas release is normally controlled by diffusion processes in the formulation, skin uptake is basically influenced by the skin conditions - normal and diseased - and the physicochemical properties of the active agent and the vehicle $[6,52]$ and currently not to be predicted by computer-assisted models [52].

Drug Release and Skin Penetration from

SLNs and a Base Cream
Uptake of the 3 steroids from the cream was studied in parallel using skin of 3 donors, and each cream was tested at least in triplicate on each skin. At the end of the exposure, the GCs were quantified in 100- $\mu \mathrm{m}$ horizontal sections of the skin up to $400 \mu \mathrm{m}$, and the total GC uptake is depicted in figure 3a. Regarding PC and BMV, varying amounts of metabolites were found in the skin. This can be a result of the esterase activity of the cryoconserved skin [53]. These data are not shown because of the potential high interindividual variation in the esterase activity, yet $\mathrm{PC}$ and $\mathrm{BMV}$ penetration is reported as total drug which is the sum of native GC plus metabolites. Applied for $6 \mathrm{~h}, 0.46 \mu \mathrm{g}$ PD had penetrated the skin, while with the others penetration was PC $0.16 \mu \mathrm{g}$ and BMV $0.12 \mu \mathrm{g}$ (median). In the first $100 \mu \mathrm{m}$ (mainly the epidermis), PD uptake from the cream exceeded PC and BMV uptake about 3-fold (fig. 3a; for mean uptake 0-400 $\mu \mathrm{m}$, see table 3 ), too. The difference between PC and BMV uptake is less obvious, but PC uptake was higher in each of the 3 donor skins. In deeper skin layers (200-400 $\mu \mathrm{m})$, the GC amounts were low for all of the 3 steroids. Although the rank order of steroid penetration and release was identical, relating GC uptake and release (ratio, table 3) shows BMV, the most lipophilic substance, to penetrate best, followed by PC. The clearly lower skin uptake ratio despite an only minor difference in lipophilicity may be due to the slightly larger molecular volume of the PD diester $\left(388.5 \mathrm{~cm}^{3} / \mathrm{mol}\right)$ and polar surface area $\left(116.2 \AA^{2}\right)$ as compared to the monoester BMV $\left(382.3 \mathrm{~cm}^{3} / \mathrm{mol}\right.$ and $\left.100.9 \AA^{2}\right)$. In fact, the rank order of the ratios of GC skin uptake and release (table 3) is in accordance with the rank order of the permeability coefficients (table 2) [39].

\section{Skin Uptake Studies: SLN}

To overcome the skin barrier, various colloidal drug carrier systems have been developed [7, 12, 54-56]. SLNs have been studied intensively, yet the mechanism of enhancement is not clarified in full; lipid interactions of carrier and skin surface have been identified as a relevant parameter $[12,13]$. Here, we studied the skin uptake of GCs loaded to SLNs and applied for $6 \mathrm{~h}$. As observed before [14, 15, 18], SLNs enhanced drug penetration into the skin. Here, for the first time we compared the enhancement for a series of agents varying in lipophilicity, molecular volume and structure of the steroid moiety.

Although the release of the steroids from cream and SLNs ranks in the same order, this does not hold true with the skin uptake of the steroids (fig. 3b). PC (2.06

Skin Pharmacol Physiol 2011;24:199-209 205 


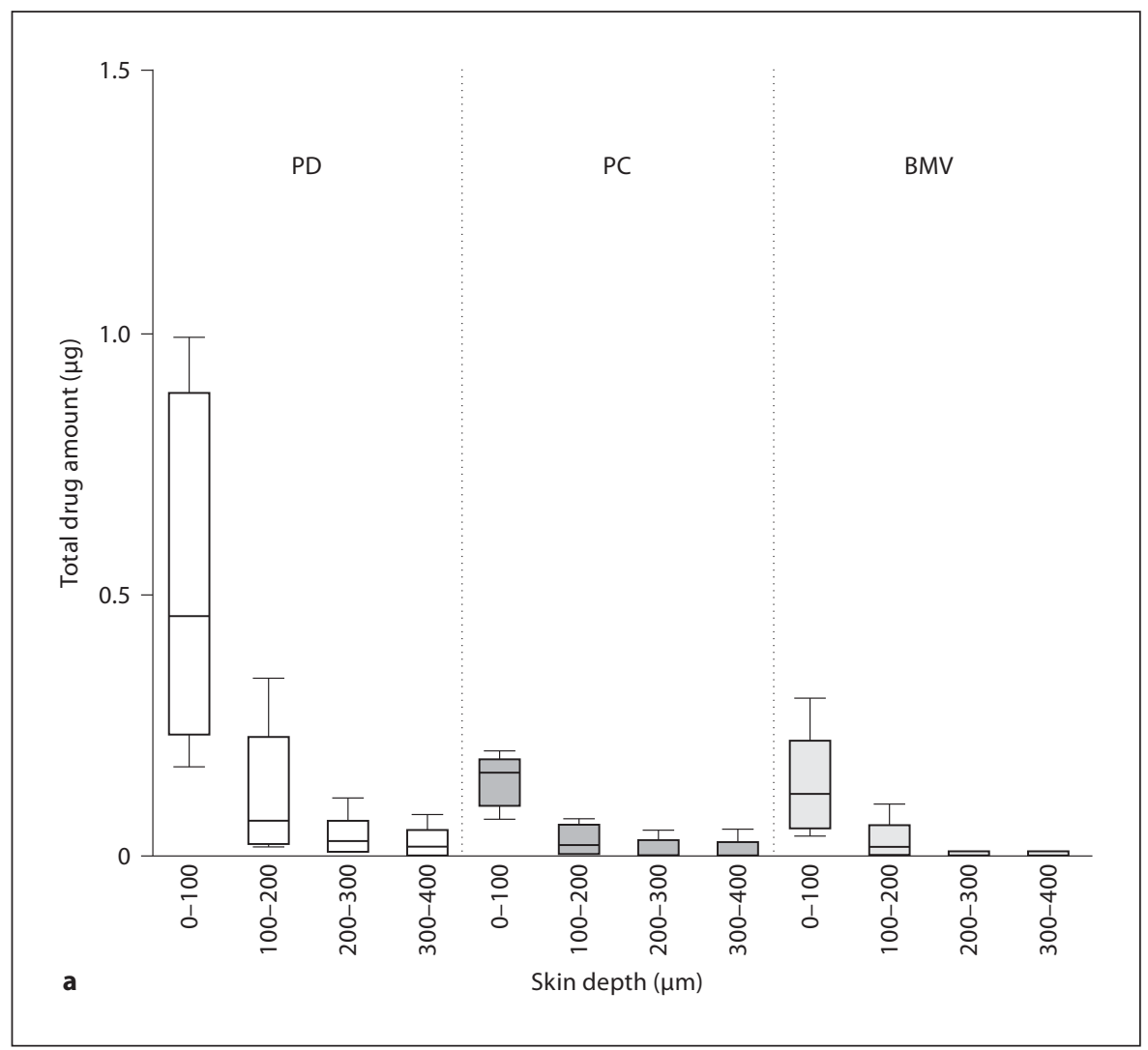

Fig. 3. Skin penetration of GCs added to base cream (a) and SLNs (b) after 6 h. Box plot with median, minimum, maximum and the 0.25 and 0.75 quartiles $(n=3)$.

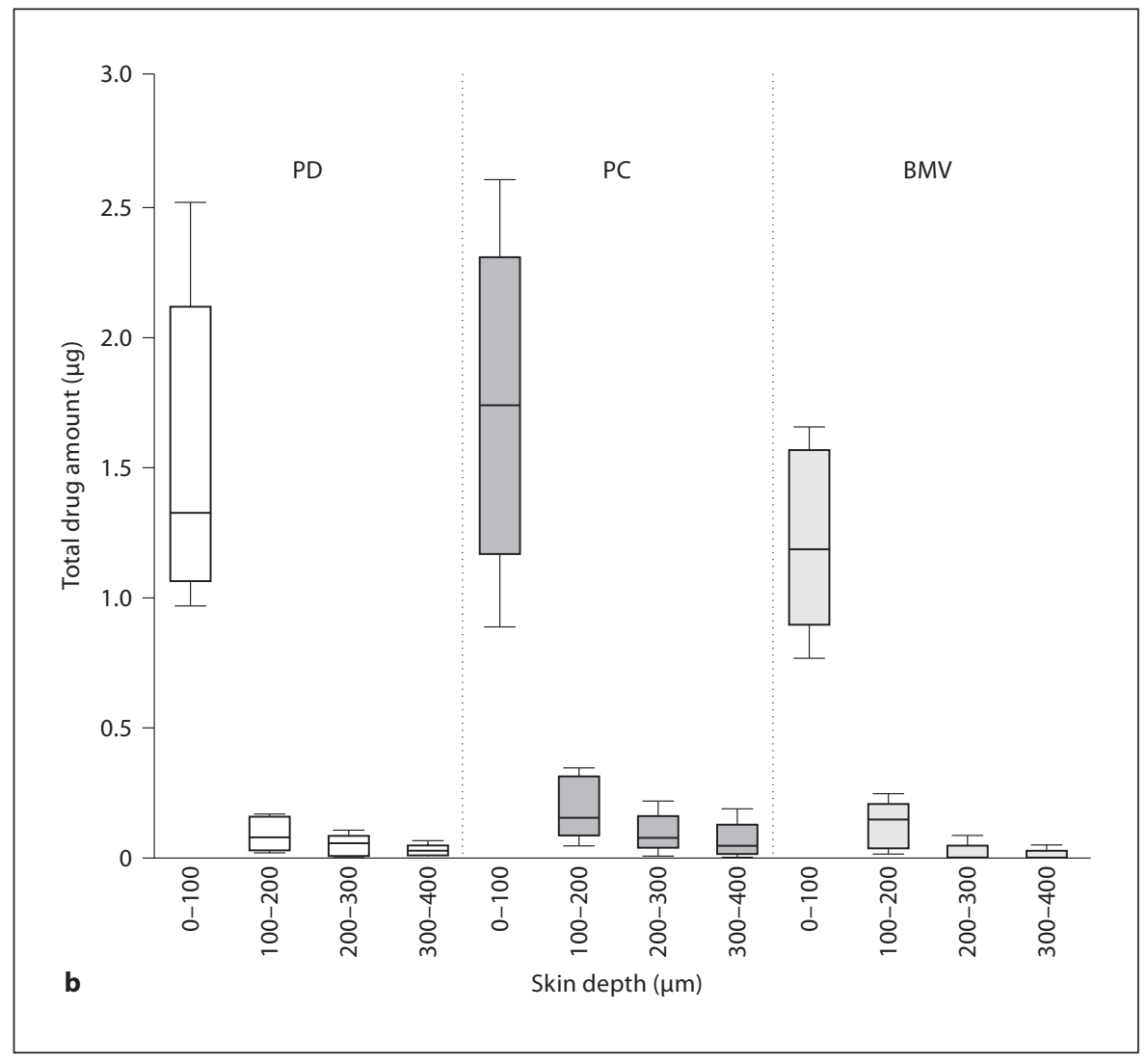


Table 3. Comparison of the GC release and uptake by human skin after $6 \mathrm{~h}$

\begin{tabular}{lclll}
\hline Formulation & $\begin{array}{l}\text { Drug released } \\
\text { after } 6 \mathrm{~h}, \mu \mathrm{g}\end{array}$ & $\begin{array}{l}\text { Total skin uptake } \\
\text { after } 6 \mathrm{~h}, \mu \mathrm{g}\end{array}$ & $\begin{array}{l}\text { Ratio of drug } \\
\text { skin uptake } \\
\text { and release, } \%\end{array}$ & $\begin{array}{l}\text { Epidermal enhancement } \\
\text { factor } \\
100 \mu \mathrm{m}: 200 \mu \mathrm{m} \\
\text { (median) }\end{array}$ \\
\hline SLN PD & $151.92 \pm 8.28$ & $1.72 \pm 0.54$ & 1.13 & 17.3 \\
SLN PC & $45.05 \pm 4.35$ & $2.06 \pm 0.70$ & 4.57 & 10.8 \\
SLN BMV & $17.95 \pm 4.11$ & $1.37 \pm 0.29$ & 7.63 & 7.9 \\
Cream PD & $38.53 \pm 3.32$ & $0.68 \pm 0.40$ & 1.76 & 6.5 \\
Cream PC & $3.48 \pm 0.12$ & $0.20 \pm 0.09$ & 5.75 & 7.2 \\
Cream BMV & $1.38 \pm 0.16$ & $0.16 \pm 0.11$ & 11.59 & 7.8 \\
\hline
\end{tabular}

Results are given as means \pm SD $(n=9$ drug release and $n=3$ skin uptake) and ratio of both in percent; the epidermal enhancement factor is calculated.

$\mu \mathrm{g})$ penetration exceeds those of $\mathrm{PD}(1.72 \mu \mathrm{g})$ and BMV (1.37 $\mu \mathrm{g} ; 0-400 \mu \mathrm{m}$, mean value; table 3$)$. The overall 1.5 -fold difference with SLN dispersion is clearly less than the approximately 4 -fold variation with GC creams. Thus, despite the importance of drug release, delivery by SLNs to the skin is strongly influenced by other properties, too.

The interaction of skin, vehicle and active ingredient controls the penetration of the active ingredient into the skin. The lipid content of a formulation can influence the thermodynamic activity of the active ingredient, resulting in a modified penetration profile [51] and penetration enhancers like oleic acid and ethanol changing the ceramide organization within the skin, and can reversibly reduce the barrier function of the stratum corneum [57]. Changes of lipid structure by Poloxamer $2.5 \%$ used for SLN stabilization have, however, been ruled out [58], and intact SLNs $175 \mathrm{~nm}$ in size should not penetrate the skin [7]. In fact, no penetration was observed with $\mathrm{TiO}_{2}$ and $\mathrm{ZnO}$ particles less than $100 \mathrm{~nm}$ in size $[59,60]$ either, as well as with Quantum dot nanoparticles about $10 \mathrm{~nm}$ in size [61]. Obviously the large surface of the SLNs most efficiently interacting with skin surface lipids [11-13] allows for a most efficient delivery to the skin surface rather independently of the lipophilicity of the agent and overruling the influences of molecular volume/molecular weight and the polar surface area of the GCs (table 1). Once more, the permeability coefficient $K_{p}$ (table 1) gains relevance as soon as the agent is released. It has to be kept in mind, however, that only 3 test agents of one substance class have been studied here. The lower penetration:release ratio when applying the SLN dispersions as with the cream indicates a saturation of the superficial skin layers due to the very efficient release from SLNs (fig. 1).

\section{Epidermal Targeting}

Differences in the cream and SLNs become even more obvious by drug distribution within the skin. Targeting to human epidermis was previously observed with the drug associated with the lipid particle surface $[15,18,19]$. Incorporating the lipophilic dye Nile red into the matrix of the lipid nanoparticles showed no targeting effect using pig skin as test matrix $[12,14]$.

Loading PD and PC to SLNs led to a clearly modified penetration profile compared to the cream (fig. $3 \mathrm{~b}$ ). This is seen with each donor skin (not shown). The epidermal enhancement given by the ratios between $0-100 \mu \mathrm{m}$ (containing the epidermis and upper parts of the dermis) and 100-200 $\mu \mathrm{m}$ (dermis only) of the skin for PC and PD was clearly higher with SLNs as compared to the cream (table 3). This does not hold true for BMV, the epidermal enhancement factors being 7.8 (cream) and 7.9 (SLN), respectively, which is well in accordance with previous results [19]. Although conclusions from these results ask for caution due to the high variation among the donors, epidermal targeting with PC and PD appears possible.

\section{Conclusion}

Taken together, loading to SLNs increased GC release compared to base cream. Although for both formulations release followed the order PD $>>$ PC $>$ BMV, only with the creams did penetration follow release. Yet, penetra- 
tion was rather independent of release and the physiochemical properties of the GCs when applying SLN dispersions, indicating the specific interaction of carrier and skin surface lipids being of high importance. This becomes possible by an intrinsic mechanism related to the lipid structure and nanosize of SLNs.

\section{Acknowledgment}

The financial support of the German Research Foundation (FG 463) is gratefully acknowledged.

\section{References}

1 Bouwstra JA, Honeywell-Nguyen PL, Gooris GS, Ponec M: Structure of the skin barrier and its modulation by vesicular formulations. Prog Lipid Res 2003;42:1-36.

$\checkmark 2$ Joshi MD, Müller RH: Lipid nanoparticles for parenteral delivery of actives. Eur Pharm Biopharm 2009;71:161-172.

$\checkmark 3$ Wissing SA, Kayser O, Müller RH: Solid lipid nanoparticles for parenteral drug delivery. Adv Drug Deliv Rev 2004;56:1257-1272.

4 Müller RH, Runge S, Ravelli V, Mehnert W, Thünemann AF, Souto EB: Oral bioavailability of cyclosporine: solid lipid nanoparticles (SLN) versus drug nanocrystals. Int Pharm 2006;317:82-89.

5 Yang S, Zhu J, Lu Y, Liang B, Yang C: Body distribution of camptothecin solid lipid nanoparticles after oral administration. Pharm Res 1999;16:751-757.

6 Pardeike J, Hommoss A, Müller RH: Lipid nanoparticles (SLN, NLC) in cosmetic and pharmaceutical dermal products. Int J Pharm 2009;366:170-184.

7 Schäfer-Korting M, Mehnert W, Korting HC: Lipid nanoparticles for improved topical application of drugs for skin diseases. Adv Drug Deliv Rev 2007;59:427-443.

$\checkmark 8$ Goebel A, Neubert RHH: Dermal peptide delivery using colloidal carrier systems. Skin Pharmacol Physiol 2008;21:3-9.

-9 Santos P, Watkinson AC, Hadgraft J, Lane ME: Application of microemulsions in dermal and transdermal drug delivery. Skin Pharmacol Physiol 2008;21:246-259.

$\checkmark 10$ Mehnert W, Mäder K: Solid lipid nanoparticles: production, characterization and applications. Adv Drug Deliv Rev 2001;47:165196.

-11 Küchler S, Herrmann W, Panek-Minkin G, Blaschke T, Zoschke C, Kramer KD, Bittl R, Schäfer-Korting M: SLN for topical application in skin diseases - characterization of drug-carrier and carrier-target interactions. Int J Pharm 2010;390:225-233.

-12 Küchler S, Radowski MR, Blaschke T, Dathe M, Plendl J, Haag R, Schäfer-Korting $M$, Kramer KD: Nanoparticles for skin penetration enhancement - a comparison of a dendritic core-multishell-nanotransporter and solid lipid nanoparticles. Eur J Pharm Biopharm 2009;71:243-250.
${ }_{13}$ Kuntsche J, Bunjes H, Fahr A, Pappinen S, Ronkko S, Suhonen M, Urtti A: Interaction of lipid nanoparticles with human epidermis and an organotypic cell culture model. Int J Pharm 2008;354:180-195.

14 Lombardi Borgia S, Regehly M, Sivaramakrishnan R, Mehnert W, Korting HC, Danker K, Röder B, Kramer KD, Schäfer-Korting M: Lipid nanoparticles for skin penetration enhancement - correlation to drug localization within the particle matrix as determined by fluorescence and parelectric spectroscopy. J Control Release 2005;110:151-163.

15 Stecova J, Mehnert W, Blaschke T, Kleuser B, Sivaramakrishnan R, Zouboulis CC, Seltmann H, Korting HC, Kramer KD, SchäferKorting M: Cyproterone acetate loading to lipid nanoparticles for topical acne treatment: particle characterisation and skin uptake. Pharm Res 2007;24:991-1000.

16 Braem C, Blaschke T, Panek-Minkin G, Herrmann W, Schlupp P, Paepenmüller T, Müller-Goyman C, Mehnert W, Bittl R, Schäfer-Korting M, Kramer KD: Interaction of drug molecules with carrier systems as studied by parelectric spectroscopy and electron spin resonance. J Control Release 2007; 119:128-135.

17 Jores K, Haberland A, Wartewig S, Mäder K, Mehnert W: Solid lipid nanoparticles (SLN) and oil-loaded SLN studied by spectrofluorometry and Raman spectroscopy. Pharm Res 2005;22:1887-1897.

-18 Santos Maia C, Mehnert W, Schaller M, Korting HC, Gysler A, Haberland A, SchäferKorting M: Drug targeting by solid lipid nanoparticles for dermal use. J Drug Target 2002;10:489-495.

19 Sivaramakrishnan R, Nakamura C, Mehnert W, Korting HC, Kramer KD, Schäfer-Korting M: Glucocorticoid entrapment into lipid carriers - characterisation by parelectric spectroscopy and influence on dermal uptake. J Control Release 2004;97:493-502.

20 Mitriaikina S, Müller-Goymann CC: Comparative permeation studies of nondiluted and diluted betamethasone-17-valerate semisolid formulations through isolated human stratum corneum and artificial skin construct. Skin Pharmacol Physiol 2009;22: 142-150.
-21 Zur Mühlen A, Mehnert W: Drug release and release mechanism of prednisolone loaded solid lipid nanoparticles. Pharmazie 1998; 53:552-555.

22 Rawle A: Basic principles of particle size analysis. Technical paper. Malvern Instruments Ltd, Worcestershire, UK 2001.

23 Siekmann B, Westesen K: Thermoanalysis of the recrystallization process of melt-homogenized glyceride nanoparticles. Colloid Surf B Biointerfaces 1994;3:159-175.

24 Blaschke T, Kankate L, Kramer KD: Structure and dynamics of drug-carrier systems as studied by parelectric spectroscopy. Adv Drug Deliv Rev 2007;59:403-410.

25 CDER: Guidance for industry: nonsterile semisolid dosage forms. 1997.

26 Shah VP, Elkins J, Lam S-Y, Skelly JP: Determination of in vitro drug release from hydrocortisone creams. Int J Pharm 1989;53: 53-59.

27 Higuchi T: Rate of release of medicaments from ointment bases containing drugs in suspension. J Pharm Sci 1961;50:874-875.

-28 Lombardi Borgia S, Schlupp P, Mehnert W, Schäfer-Korting M: In vitro skin absorption and drug release - a comparison of six commercial prednicarbate preparations for topical use. Eur J Pharm Biopharm 2008;68:380389.

-29 Niedorf F, Schmidt E, Kietzmann M: The automated, accurate and reproducible determination of steady-state permeation parameters from percutaneous permeation data. Altern Lab Anim 2008;36:201-213.

30 OECD: OECD guidelines for the testing of chemicals. No 428: Skin absorption: in vitro method. 2004.

31 Schäfer-Korting M, Bock U, Diembeck W, Düsing HJ, Gamer A, Haltner-Ukomadu E, Hoffmann C, Kaca M, Kamp H, Kersen S, Kietzmann M, Korting HC, Krächter HU, Lehr CM, Liebsch M, Mehling A, MüllerGoymann C, Netzlaff F, Niedorf F, Rübbelke MK, Schäfer U, Schmidt E, Schreiber S, Spielmann H, Vuia A, Weimer M: The use of reconstructed human epidermis for skin absorption testing: results of the validation study. Altern Lab Anim 2008;36:161-187. 
>32 Gysler A, Lange K, Korting HC, SchäferKorting M: Prednicarbate biotransformation in human foreskin keratinocytes and fibroblasts. Pharm Res 1997;14:793-797.

33 Kubota K, Ademola J, Maibach HI: Simultaneous diffusion and metabolism of betamethasone 17-valerate in the living skin equivalent. J Pharm Sci 1995;84:1478-1481.

34 Gysler A, Kleuser B, Sippl W, Lange K, Korting HC, Höltje HD, Korting HC, SchäferKorting M: Skin penetration and metabolism of topical glucocorticoids in reconstructed epidermis and in excised human skin. Pharm Res 1999;16:1386-1391.

35 Kubota K, Ademola J, Maibach HI: Metabolism and degradation of betamethasone 17-valerate in homogenized living skin equivalent. Dermatology 1994;188:13-17.

-36 Ryatt KS, Feather JW, Mehta A, Dawson JB, Cotterill JA, Swallow R: The stability and blanching efficacy of betamethasone-17-valerate in emulsifying ointment. Br J Dermatol 1982;107:71-76.

-37 El Maghraby GM, Williams AC, Barry BW: Drug interaction and location in liposomes: correlation with polar surface areas. Int J Pharm 2005;292:179-185.

38 Ertl P, Rohde B, Selzer P: Fast calculation of molecular polar surface area as a sum of fragment-based contributions and its application to the prediction of drug transport properties. J Med Chem 2000;43:3714-3717.

39 Potts RO, Guy RH: Predicting skin permeability. Pharm Res 1992;9:663-669.

40 Souto EB, Müller RH: Lipid nanoparticles: effect on bioavailability and pharmacokinetic changes; in Schäfer-Korting M (ed): Handbook of Experimental Pharmacology. Berlin, Springer, 2009, vol 197: Drug delivery, pp 115-141.

-41 Schubert MA, Schicke BC, Müller-Goymann CC: Thermal analysis of the crystallization and melting behavior of lipid matrices and lipid nanoparticles containing high amounts of lecithin. Int J Pharm 2005;298: 242-254.
42 Guttman DE, Meister PD: The kinetics of the base-catalyzed degradation of prednisolone. J Am Pharm Assoc (Baltim) 1958;47:773778.

43 Oesterling TO, Guttman DE: Factors influencing stability of prednisolone in aqueous solution. J Pharm Sci 1964;53:1189-1192.

44 Guy RH, Hadgraft J: On the determination of drug release rates from topical dosage forms. Int J Pharm 1990;60:R1-R3.

45 Higuchi WI: Analysis of data on the medicament release from ointments. J Pharm Sci 1962;51:802-804.

46 Higuchi T: Physical chemical analysis of percutaneous absorption process from creams and ointments. J Soc Cosmet Chem 1960;11: 85-97.

47 Zur Mühlen A, Schwarz C, Mehnert W: Solid lipid nanoparticles (SLN) for controlled drug delivery - drug release and release mechanism. Eur J Pharm Biopharm 1998;45:149155.

48 Spireas S, Sadu S: Enhancement of prednisolone dissolution properties using liquisolid compacts. Int J Pharm 1998;166:177-188.

49 Ibekwe VC, Fadda HM, Parsons GE, Basit AW: A comparative in vitro assessment of the drug release performance of $\mathrm{pH}$-responsive polymers for ileo-colonic delivery. Int J Pharm 2006;308:52-60.

50 Müller RH, Mäder K, Gohla S: Solid lipid nanoparticles (SLN) for controlled drug delivery - a review of the state of the art. Eur J Pharm Biopharm 2000;50:161-177.

51 Wirén K, Frithiof H, Sjoqvist C, Loden M: Enhancement of bioavailability by lowering of fat content in topical formulations. $\mathrm{Br} \mathrm{J}$ Dermatol 2009;160:552-556.

$\checkmark 52$ Moss GP, Dearden JC, Patel H, Cronin MT: Quantitative structure-permeability relationships (QSPRS) for percutaneous absorption. Toxicol In Vitro 2002;16:299-317.
53 Hewitt PG, Perkins J, Hotchkiss SA: Metabolism of fluroxypyr, fluroxypyr methyl ester, and the herbicide fluroxypyr methylheptyl ester. I. During percutaneous absorption through fresh rat and human skin in vitro. Drug Metab Dispos 2000;28:748-754.

54 Cevc G: Lipid vesicles and other colloids as drug carriers on the skin. Adv Drug Deliv Rev 2004;56:675-711.

55 Cosco D, Celia C, Cilurzo F, Trapasso E, Paolino D: Colloidal carriers for the enhanced delivery through the skin. Expert Opin Drug Deliv 2008;5:737-755.

56 Date AA, Patravale VB: Microemulsions: applications in transdermal and dermal delivery. Crit Rev Ther Drug Carrier Syst 2007;24: 547-596.

-57 Guillard EC, Laugel C, Baillet-Guffroy A: Molecular interactions of penetration enhancers within ceramides organization: a FTIR approach. Eur J Pharm Sci 2009;36: 192-199.

58 Blaschke T, Spangenberg T, Schlupp P, Dathe M, Szcymczak W, Mehnert W, Korting HC, Thalhammer S, Niehus H, Schäfer-Korting M, Kramer KD: Interaction of drug-carrier systems with targets - a study using atomic force microscopy. Pharmazie 2010;65:657664.

59 Filipe P, Silva JN, Silva R, Cirne de Castro JL, Marques Gomes M, Alves LC, Santus R, Pinheiro T: Stratum corneum is an effective barrier to $\mathrm{TiO}_{2}$ and $\mathrm{ZnO}$ nanoparticle percutaneous absorption. Skin Pharmacol Physiol 2009;22:266-275.

60 Nohynek GJ, Dufour EK, Roberts MS: Nanotechnology, cosmetics and the skin: is there a health risk? Skin Pharm Phys 2008;21:136149.

61 Zhang LW, Monteiro-Riviere NA: Assessment of quantum dot penetration into intact, tape-stripped, abraded and flexed rat skin. Skin Pharmacol Physiol 2008;21:166-180. 